\title{
Retrieval of vegetation clumping index using hot spot signatures measured by POLDER instrument
}

\author{
Roselyne Lacaze $^{\mathrm{a}, *}$, Jing M. Chen ${ }^{\mathrm{b}}$, Jean-Louis Roujean ${ }^{\mathrm{a}}$, Sylvain G. Leblanc ${ }^{\mathrm{c}}$ \\ ${ }^{\mathrm{a}}$ GAME/CNRM (Météo France/CNRS), 42, avenue Gaspard Coriolis, 31057 Toulouse Cedex, France \\ ${ }^{\mathrm{b}}$ University of Toronto, 100 St. George Street, Room 5047, Toronto, Ontario, Canada M5S $3 G 3$ \\ ${ }^{\mathrm{c} C}$ Canada Center for Remote Sensing, 588 Booth Street, Ottawa, Ontario, Canada K1A 0Y7
}

Received 26 January 2001; received in revised form 24 May 2001; accepted 26 May 2001

\begin{abstract}
The potential use of the information from a sampling of the bidirectional reflectance distribution function (BRDF) has suffered from the lack of solid applications in ecology, where it is expected to play the role of an advanced descriptor of vegetation as a complement to hyperspectral measurements. Such a shortcoming stems from the lack of consistent angular data sets with an adequate resolution at global scale. In this context, the POLDER instrument is particularly relevant because it acquires directional radiance signatures at a high angular resolution and thereby provides the first global BRDF product. In this paper, we investigate how to discriminate vegetation types in using only a portion of the BRDF, in particular, the two paramount directional signatures, which are the maximum (hot spot) and the minimum (dark spot) of reflectance observed in the backscattering and forward scattering regions, respectively. A directional index hot-dark spot (HDS) is formulated using these two signatures. It is defined as the normalized difference between the reflectances at the hot spot and dark spot. It is shown that the HDS can be linearly related with the foliage clumping index for three different vegetation types observed by the spaceborne POLDER sensor. The significance of the clumping index mapping for ecological studies is evaluated using the Boreal Ecosystem Productivity Simulator (BEPS). Considering foliage clumping in BEPS, the estimation of daily canopy photosynthesis can differ about $20 \%$ for a black spruce site. In this context, it is expected that the findings of this study will have a strong impact on the use of directional optical remote sensing to improve the assessment of terrestrial productivity and carbon cycle. (C) 2002 Elsevier Science Inc. All rights reserved.
\end{abstract}

\section{Introduction}

Recent terrestrial carbon cycle studies have emphasized the need to characterize the spatial distribution of carbon balance because the distribution pattern will help understand the mechanisms of the terrestrial carbon sinks and predict the future trends (Chen, Chen, Liu, \& Cihlar, 2000; Schimel, 1995). Satellite remote sensing methods are believed to have the potential to achieve this goal (Cihlar, Denning, \& Gosz, 2000; Field, Randerson, \& Malmstrom, 1995; Running, Loveland, \& Pierce, 1994). Optical satellite sensors, such as AVHRR and VEGETATION, have allowed us to measure vegetation cover types and density to a first approximation. The traditional and mature methods for deriving vegetation characteristics utilize remote sensing observations near or normalized to nadir. The angular variations of the radiometric signal are often treated as noise and then removed

\footnotetext{
* Corresponding author.
}

through an angular normalization procedure (Leroy \& Roujean, 1994). However, more information could be gained from the multiangular remote sensing for ecological and biological studies (Asner, 2000; Asner, Braswell, Schimel, \& Wessman, 1991). There have been limited cases demonstrating the utility of multiple angle measurements (Diner et al., 1999; Sandmeier \& Deering, 1999). After our first attempt in using an angular index to characterize the three-dimensional (3-D) vegetation structure (Chen, Liu, Leblanc, Roujean, \& Lacaze, 2001), the purpose of this paper is to further investigate the methodology and present conclusive results.

Vegetation at the Earth's surface has various levels of foliage organization. Herbaceous canopies (crops and grass) generally have simple structures with leaves more or less randomly distributed with respect to their angle and spatial positions, whereas forests are often highly organized with leaves distributed in structures at various hierarchical levels, such as shoots, branches, whorls, tree crowns, and tree groups. While these structures exist for various ecological 
reasons, their effects are often ignored in plant growth and terrestrial carbon cycle modeling. In particular, in remote sensing applications for large areas, such detailed information is often not available. However, these structures affect not only the interaction of radiation with vegetation but also plant growth and carbon cycle. While detailed consideration of the effects of these structures is not yet possible, the accuracy of our estimation of radiation interception by the canopy and the canopy photosynthesis can be greatly improved if we can introduce one more parameter to characterize the general level of organization of foliage in the canopy in addition to the commonly used leaf area index (LAI) as a structural parameter. This additional parameter may be the foliage dispersion parameter first introduced by Nilson (1971). As plant leaves are more often grouped together than regularly spaced relative to the random distribution case, it is often termed as the foliage clumping index. Chen (1996) developed an optical instrument called Tracing Radiation and Architecture of the Canopy (TRAC), which can measure the clumping index, making it possible to quantify the clumping index of plant canopies. This single clumping index can be used to quantify the total effect of canopy structures at all levels on radiation interception and photosynthesis by the canopy.

This clumping index has been used in mapping the net primary productivity of a northern area using Boreal Ecosystem Productivity Simulator (BEPS; Liu, Chen, Cihlar, \& Park, 1997). In the implementation of BEPS based on satellite-derived products of land cover and LAI, constant clumping index values were assigned to different cover types according to limited TRAC measurements. Although the method is an improvement from those without considering canopy architecture, the estimation is only a crude first approximation as large ranges of the clumping index were measured by TRAC for the same cover types. It is therefore highly desirable to be able to map this structural parameter in addition to LAI.

The advent of the airborne and spaceborne POLDER sensors providing multiple spectral images at high angular resolutions has made it possible to explore the feasibility of retrieving the clumping index from multiangular observations. The basis for this effort is that a structurally complex surface enhances the anisotropy of reflected solar radiance relative to the case of a smooth surface. The degree of foliage organization may therefore be manifested in the degree of the anisotropy of the reflected radiance. We report on an effort to utilize both airborne and spaceborne POLDER data to estimate the clumping index and to evaluate these retrievals against ground TRAC data collected in Canada. The specific objectives of this paper are (1) to present an angular index quantifying the degree of anisotropy of the reflected radiance, (2) to investigate the correlation of the index with canopy architecture characterized by the clumping index, and (3) to discuss the significance of using the clumping index in terrestrial carbon cycle estimation.

\section{Description of POLDER data sets}

The POLDER radiometer is designed to measure the directional and polarized reflectances of the surface-atmosphere system (Deschamps et al., 1994). The instrument concept consists of a rotating wheel equipped with and without polarized filters, a CCD matrix array detector, and a wide field of view lens $\left(114^{\circ}\right)$. During a single satellite overpass, a surface target is scanned up to 14 times under different viewing angles. The view illumination directional configuration changes each day as the orbit shifts. Therefore, after a few days, assuming clear atmospheric conditions, the measurements provide a sample of the bidirectional reflectance distribution function (BRDF) within the sensor field of view.

\subsection{Spaceborne measurements}

The POLDER sensor onboard the Japanese satellite platform ADEOS has measured the reflectance of the entire land-atmosphere terrestrial system in the period between November 1996 and June 1997. For each orbit, global POLDER data sets were coregistered, calibrated, cloud screened, and atmospherically corrected in order to obtain land surface reflectance products at $6 \mathrm{~km}$ resolution (Bréon \& Colzy, 1999; Leroy et al., 1997). The atmospheric correction was applied to each clear pixel to remove the effects of stratospheric aerosols, absorbing gases $\left(\mathrm{O}_{3}, \mathrm{O}_{2}\right.$, and $\mathrm{H}_{2} \mathrm{O}$ ), and molecular scattering with input parameters as concomitant as possible. No correction for tropospheric aerosols was carried out although there exists a potential to characterize them from visible polarized measurements (Herman, Deuzé, Devaux, Bréon, \& Tanré, 1997; Leroy et al., 1997).

In this study, we consider POLDER BRDF and hot spot observations over Canada. The BRDF quality for a given thematic biome can be improved by gathering more angular measurements for a large number of pixels observed with different geometric conditions. For such an effort, a land cover map of Canada based on 1995 AVHRR data (Cihlar, Beaubien, Latifovic, \& Simard, 1999) with a $1 \mathrm{~km}$ resolution was considered to select the pixels of a same vegetation type. First, the original land cover map with 31 classes was transformed into a 12class map by combining similar cover types. Next, a $7 \times 7$ pixel window was moved over the map to find POLDER pixel-size areas containing only one cover type. When all 49 pixels in the window were of the same cover type, the central pixel was set to this class. In the cases when one or more of the 49 pixels were not the same as the dominant cover type, the central pixel was rejected. The resulting map has shown that uniform grassland areas were located in the South of Saskatchewan and Alberta and that evergreen forests were essentially set on Western Ontario and on the Northern coast of Quebec with a few patches in the Rocky Mountains. Continuous deciduous broadleaf forests 
were found in the Eastern Canada along the US border. For the present study, pixels of $7 \times 7 \mathrm{~km}^{2}$ representing the three cover types were then selected in these respective areas. Through this screening process, we retained 50 sites of conifer forest and 30 sites of broadleaf forest and grassland. During May and June 1997, POLDER observations provided 68,47 , and 32 hot spot configurations for conifer, broadleaf, and grassland, respectively.

\subsection{Airborne measurements}

Reflectance measurements with POLDER were collected at several dates from a NASA aircraft and a helicopter during the BOREAS 1994 experiment (Sellers et al., 1997) over the sites OA (old aspen), OBS (old black spruce), OJP (old jack pine), and YJP (young jack pine) of Southern Study Area (SSA). Additional measurements over a pasture site were also made. The airborne POLDER sensor is similar to the spaceborne version. Onboard the helicopter at a flight altitude of approximately $300 \mathrm{~m}$, a ground resolution of about $2 \mathrm{~m}$ was achieved. The resulting footprint was $35 \mathrm{~m}$ with a $8^{\circ}$ increment from the $\mathrm{C}$ 130 aircraft, which flew typically about $5500 \mathrm{~m}$ altitude (Bréon et al., 1997). Data acquisition over a given site required a short time period during which the sun position did not change considerably.

Radiometric calibration was performed at the Laboratoire d'Optique Atmosphérique (LOA) before and after the BOREAS experiment using an integrating sphere of known radiance. The derived values of the absolute calibration coefficients are alike, with average peak discrepancies on the order of $3-5 \%$ depending on the band. Data sets were atmospherically corrected by using the $6 \mathrm{~S}$ code (Vermote, Tanré, Deuzé, Herman, \& Mocrette, 1997) in order to get surface reflectance. A main input of the correction algorithm is the aerosol optical depth of the full atmosphere and that below the aircraft. Such values are interpolated here to 550 $\mathrm{nm}$ from measurements given in the BOREAS Information System (BORIS) database. All flight days were permanently clear and the mean aerosol optical depth was 0.11 . It was considered herein a midarctic summer atmospheric model and a continental type for aerosols.

\section{Modeling the directional signatures}

The modeling of the hot spot signature relies on the theory of radiative transfer (RT) for a turbid medium including a statistical distribution of the gap probability (Gerstl, Simmer, \& Powers, 1986; Kuusk, 1985; Verstraete, Pinty, \& Dickinson, 1990) or on a geometric-optical (GO) approach (Jupp \& Strahler, 1991). The third approach is a combination of RT and GO approaches (Chen \& Leblanc, 1997; Qin \& Xiang, 1994). Such models have revealed the extreme sensitivity of the hot spot reflectance to the architecture of vegetation canopies and its gap size fraction and have proved to be efficient for simulating the phenomenon when they are forced in a direct mode. However, more relevant results of model inversion studies have been using synthetic data sets. Very few attempts have been made using actual remote sensing data due to insufficient angular resolution and the lack of routine observations of the phenomenon. In this respect, the feasibility of retrieving the structural properties of vegetation from satellite hot spot observations is a challenge. The POLDER/ADEOS mission fosters such an investigation since it was shown that the hot spot effect is a major feature of the BRDF for terrestrial biomes (Hautecoeur \& Leroy, 1998).

\subsection{Physical statement of the GHOST model}

Undulating signatures and a strong hot spot are the dominant features of the BRDF collected at high spatial resolution over boreal forests as reported by Bréon et al. (1997). The recent development of the GHOST reflectance model, aimed at simulating the hot spot effect, has proven that such observations are related to the local tree architecture and distribution (Lacaze \& Roujean, 2001). The basis of this model is summarized in Appendix A for convenience.

A semiinfinite slab of conic-shaped crowns with randomly distributed green foliage and woody elements represents the canopy. The model simulates the single and multiple scattering processes within individual crowns (see Appendix A). The hot spot effect is considered as a coupling between the downgoing and the outgoing pathways of a light beam undergoing a single scattering event within the canopy since it is recognized that the phenomenon is only weakly affected by higher orders of scattering (Hapke, 1986; Qin \& Goel, 1995). This approach relies on an equal probability between the events to observe a portion of shadows and to see only a portion of sunlit areas, both events becoming equivalent in the hot spot geometry. The GHOST model is able to mimic the local hot spot features observed over discontinuous boreal forests sketched as regularly shaped crowns separated by gaps. This provides a means to account for the stem density of the canopy. Parameters characterizing the architecture and distribution of trees appear in the expression of the G-function (see Appendix A). At local scale, the light penetration is enhanced in the direction parallel to the outline of the crowns, and for a patch scale landscape displaying a nonuniform density of trees, the dominant direction of light penetration corresponds to the dominant gap size fraction.

Although the GHOST model is particularly designed to investigate the RT within forests, it is also suitable to study simpler vegetation canopies like crops and pasture (see Lacaze \& Roujean, 2001). Previous comparisons with measurements at high spatial resolution over forested and agricultural lands have indicated a standard error less than 0.02 in reflectance value. In addition, it appeared that the magnitude and shape of the hot spot peak show similar features between airborne and spaceborne POLDER measurements (see 
Lacaze \& Roujean, 2001), which supported an application of the GHOST model at coarse scale resolution. Furthermore, the hot spot peaks in the satellite images do not appear as angularly narrow as predicted by 3-D RT models. Such finding supports the idea that, for large pixels, the hot spot effect is dominated by the radiation transmission between the gaps of macroscale elements forming the landscape such as groups of trees instead of microscale elements like needles. Clearly, it appears questionable how different scales contribute to the hot spot phenomenon, but here, the clumping index will concern the subpixel vegetation cover rather than the grouping of needles.

\subsection{The inversion procedure}

For GHOST model application, the inversion procedure consists of a step-by-step retrieval of each parameter. Parameters are classified into primary parameters (single scattering albedo, effective $\mathrm{LAI}_{\mathrm{e}}$ ) and secondary parameters (architectural parameters). Primary parameters are retrieved first. The single scattering albedo represents the optical properties and is retrieved from reflectance data in forward scattering region that is poorly affected by the hot spot effect. For its determination, a high initial value of $\mathrm{LAI}_{e}$ is assumed because the forward scattering signal is relatively less sensitive to it. Then, $\mathrm{LAI}_{\mathrm{e}}$ is inferred from backscattered measurements since it controls the magnitude of the hot spot reflectance. In practice, it is difficult to get hot spot measurements, then the inversion procedure for $\mathrm{LAI}_{\mathrm{e}}$ is arbitrarily defined to apply only for scattering angle within $10^{\circ}$ from the hot spot geometry. Secondary parameters are more scale dependent and their interpretation is related to the dominant vegetation units at the sampling resolution. For instance, they are representative of individual trees at local scale and of groups of trees at patch scale, thereby determining the gap size fraction and the level of discontinuity of the medium. They are obtained from the model inversion over limited angular domains with selected initial guess defined from the sensitivity study conducted by Lacaze and Roujean (2001). These same authors showed that secondary parameters can lead to a physical determination of a clumping index to be detailed in Section 3.3, thereby proving its independence with true LAI. For each parameter, the iterative procedure sweeps a number of values within the physical domain of variations and keeps the one that minimizes a simple error function. The larger range of directions, the better are the performances of the overall method. In this context, the angular diversity of the data set offered by multidirectional sensor systems is essential.

\subsection{Definition of a directional index}

Comparison of GHOST simulations with POLDER data has demonstrated that the hot spot signature influences the BRDF more than a few degrees around the sun's direction. Indeed, the phenomenon explains most of the reflectance variations observed in the principal plane. In the forward scattering direction, a very low reflectance is observed and referred here as "dark spot" (Fig. 1). This phenomenon could be the result of a volume scattering process since, for instance, the phase function selected in GHOST (see Appendix A) presents a minimum in this direction, located at $\theta_{\mathrm{S}}+\theta_{\mathrm{V}}=\pi / 2$ for similar reflectance and transmittance values. Another physical explanation is purely geometric by assuming that the sensor observes the largest proportion of shadows, which yields a minimum value of reflectance. Therefore, the angular position of the dark spot will depend on the arrangement of the crowns in the viewed area. According to this latter hypothesis, the identity and intrinsic properties of land targets are given by the enhanced contrast between the hot spot peak and the forward scattering

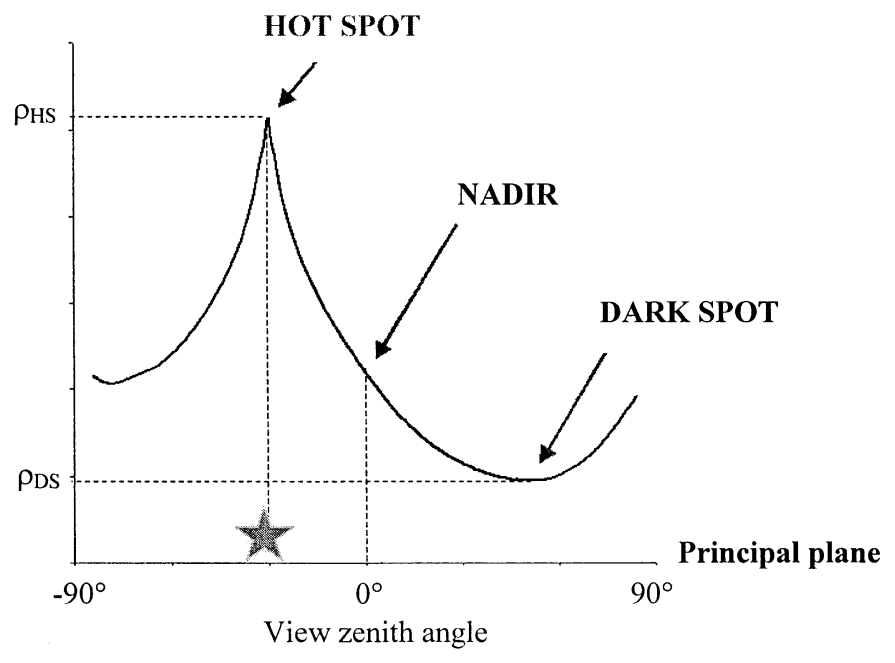

Fig. 1. Scheme of the hot spot and dark spot positions on the directional signature in the principal plane. 
depletion. As a result, we define a directional index hotdark spot (HDS) as the normalized difference between the hot spot reflectance, $\rho_{\mathrm{HS}}$, and the dark spot reflectance, $\rho_{\mathrm{DS}}$ :

$\mathrm{HDS}=\frac{\rho_{\mathrm{HS}}-\rho_{\mathrm{DS}}}{\rho_{\mathrm{DS}}}$

The shape of the reflectance curve between the hot spot and the dark spot directions will thus depend on the radiation transmission through the canopy. It is controlled by gap size fractions and probabilities both between and within crowns (Chen \& Leblanc, 1997), since the conifer forest displays a multilevel grouping: needles on shoots, shoots on branches, branches into crowns, and crowns on the patch (Chen, 1996; Oker-Blom, Lappi, \& Smolander, 1991). Such a vegetation organization is well represented by the clumping index ( $\Omega$; Nilson, 1971), which measures both the foliage aggregation into crown and the crown arrangement at the landscape scale (Chen \& Black, 1991). Such a grouping allows gap probability deviates from a Beer's law extinction (Ni, Li, Woodcock, Roujean, \& Davis, 1997; Roujean, 1999), and a sensor will see less sunlit elements in a clumped canopy than in a random medium. Consequently, the dark spot reflectance will tend to be lower and the HDS to be higher. Based on this argument, it was found to be relevant to study the

\section{CONIFER}
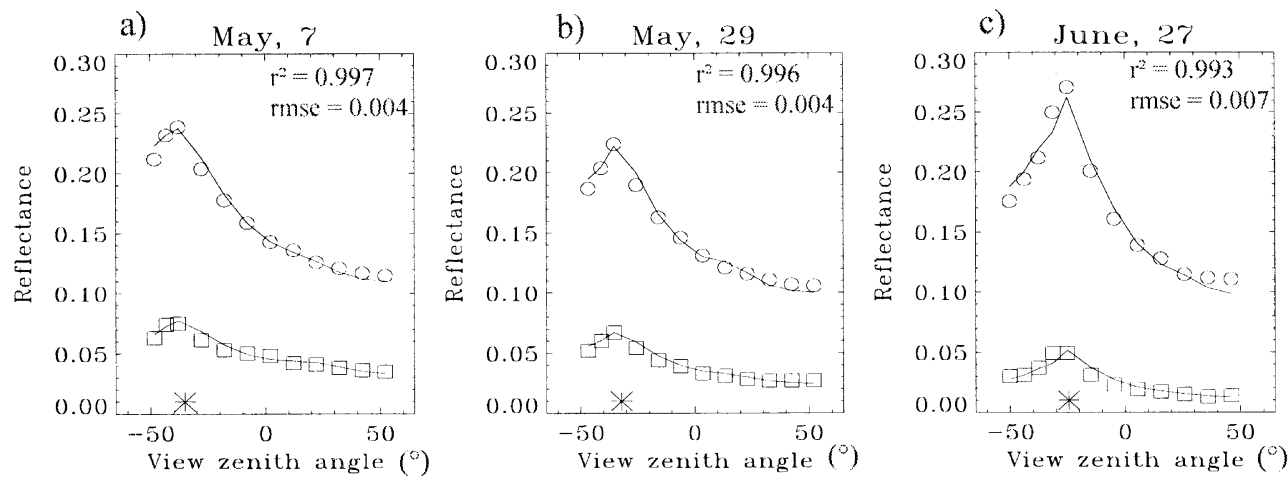

BROADLEAF
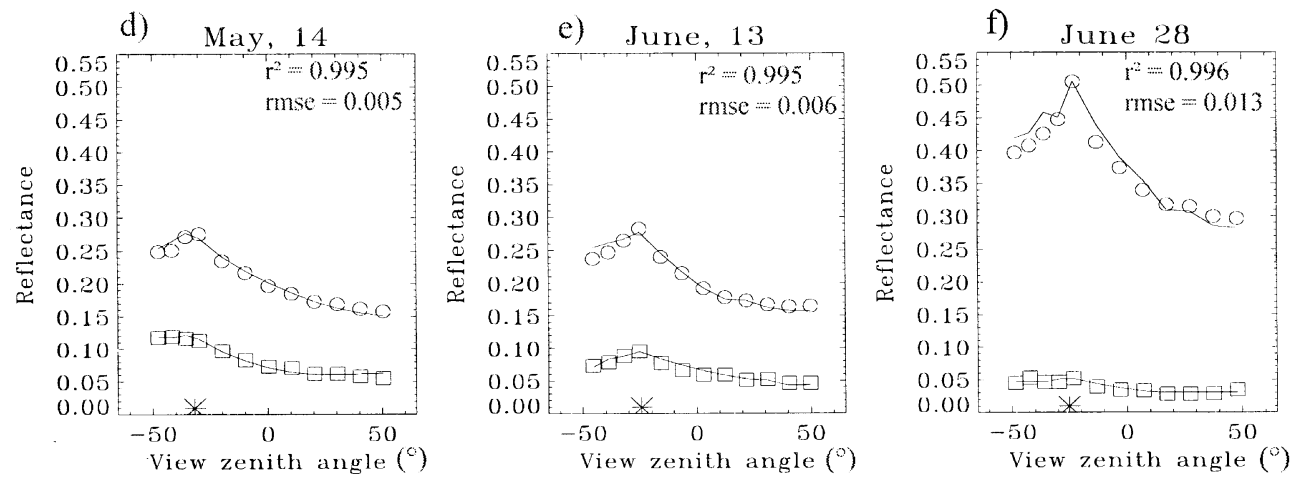

GRASSLAND
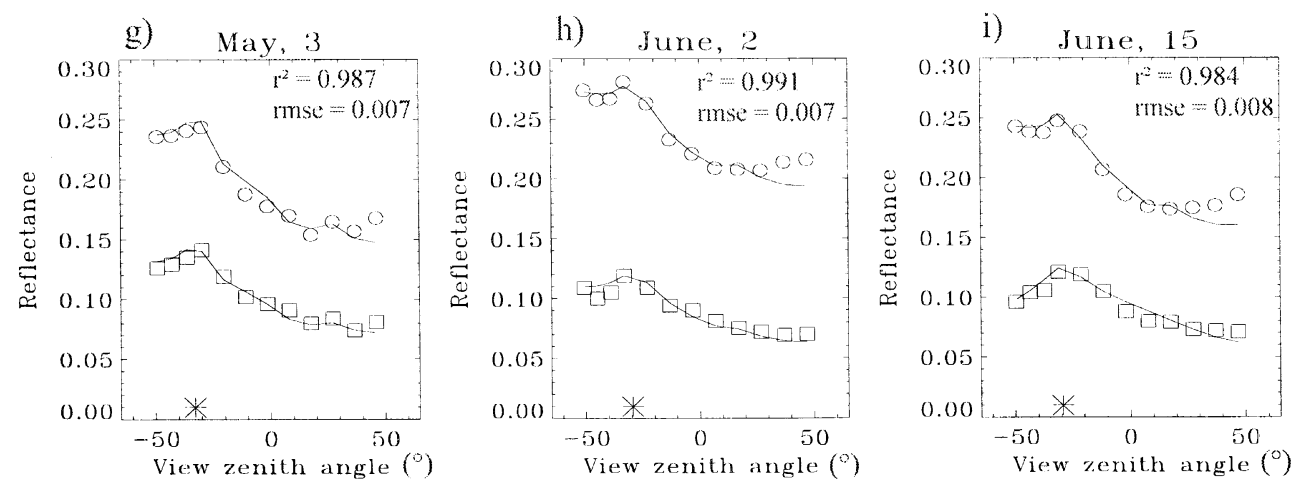

Fig. 2. Comparison of spectral signatures measured by POLDER/ADEOS at $670(\square)$ and 865 (O) nm and simulated by GHOST model ( - ) over three vegetation types. The sun is represented by a symbol (*). Presented statistics refer to both spectral data sets. 
relationship between the HDS ratio and the clumping index $(\Omega)$.

\section{Results of comparison}

Examples of GHOST simulations in comparison with spaceborne POLDER data are displayed in Fig. 2. They are in excellent agreement with the observations for the various sampled canopies, especially around the hot spot direction. It appears that conifer forests remain almost unchanged in the range period from early May to end of June, with a magnitude of near infrared hot spot peak around 0.25 . On the other hand, the mean visible reflectance decreases from around 0.05 to 0.03 (Fig. $2 \mathrm{a}-\mathrm{c}$ ). In contrast, the seasonal evolution of broadleaf forests is noticeable. Starting in May, the appearance and development of the green leaves yield a decrease of the red reflectance from 0.1 to 0.05 and an increase of the near infrared reflectance from 0.2 to 0.4 until end of June (Fig. 2d-f). As for grassland, the near infrared signature presents a reflectance increase at far off-nadir zenith angles in the forward scattering direction, which is
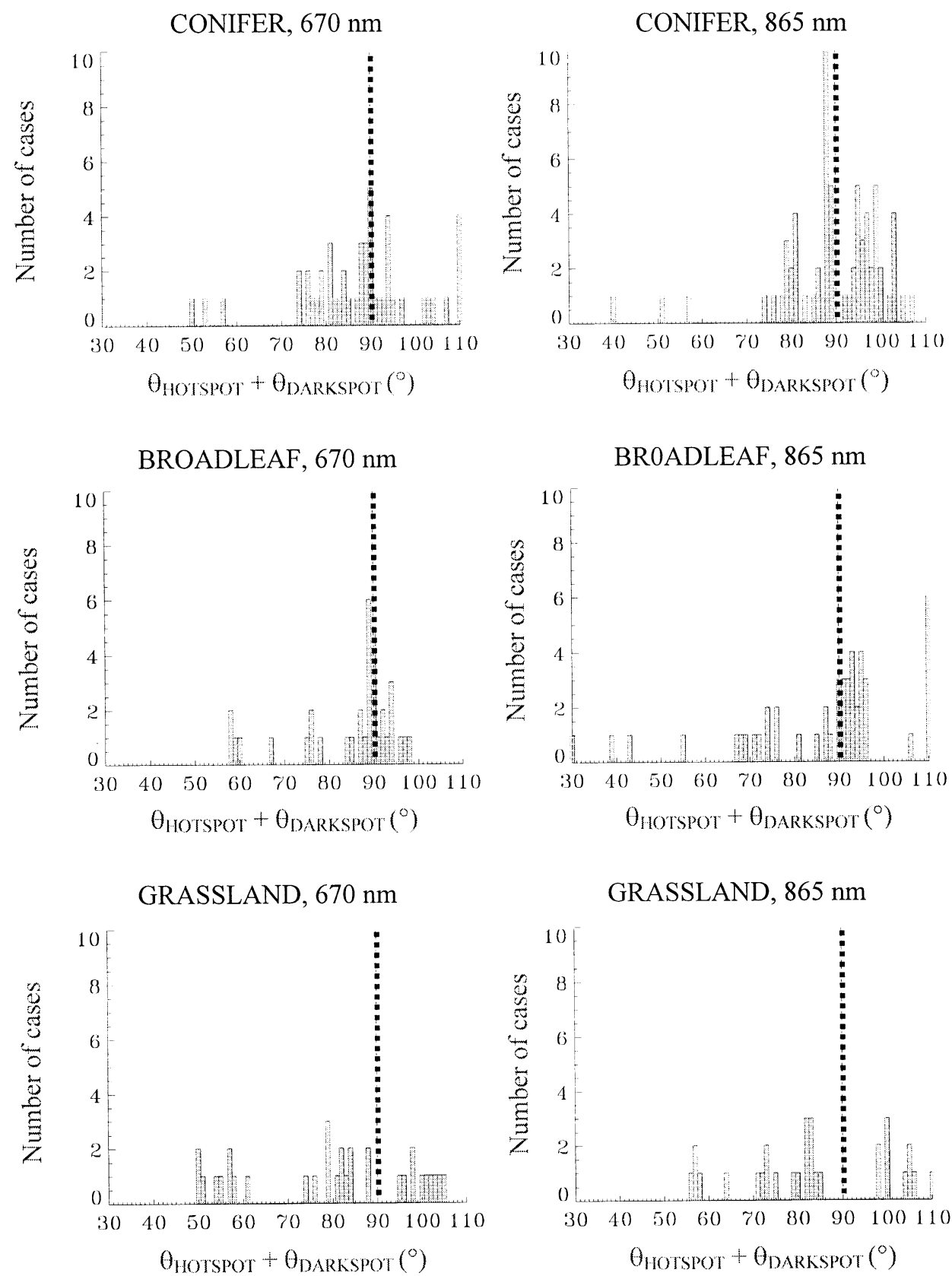

Fig. 3. Statistical distribution of the scattering angle $\left(\theta_{\mathrm{S}}+\theta_{\mathrm{V}}\right)$ for the three vegetation types instrumented by POLDER/ADEOS. The position $\theta_{\mathrm{S}}+\theta_{\mathrm{V}}=\pi / 2$, characterizing the scattering processes simulated by the phase function, is indicated by 
not well accounted for by the GHOST model as compared to the hot spot peak (Fig. $2 \mathrm{~g}-\mathrm{i}$ ). In this paper, we will consider only results of comparison for which the coefficient of determination $r^{2}$ is beyond 0.8 . This holds 48,35 , and 32 cases for conifer forest, broadleaf forest, and grassland, respectively, at $670 \mathrm{~nm}$ and 67,47 , and 30 cases at 865 $\mathrm{nm}$, being $88 \%$ of the whole sample.

The parameters retrieved from the inversion of the GHOST model serve as inputs to simulate the scene reflectance in the principal plane at $\theta_{\mathrm{S}}=30^{\circ}$, which geometry corresponds roughly to the acquisition of clumping measurements since its relationship with HDS is solar dependent. Note also that values of $\theta_{\mathrm{S}}$ around $30^{\circ}$ relate more to the crown clumping, which is the useful gap fraction to investigate the upscaling issue at patch scale (see Roujean, 1999). A statistical distribution of a scattering angle formed by the angular position of the dark spot relatively to the sun position is shown (Fig. 3). This position is highly variable and the phenomenon has no link with the phase function. Rather, the tree distribution patterns forming discontinuous patches within the pixels may be the cause of the irregular angular position of the dark spot relative to the sun. Hence, geometric effects seem to be at the root of the dark spot signature.

The above finding that shadows are responsible for the dominant signature in forward scattering region supports the utility of hot spot and dark spot signatures as proposed in the directional index of Eq. (1) to assess the level of foliage aggregation as well as discontinuity vegetation on the landscape. We investigated the relationship between the directional index HDS and the clumping index $\Omega$ for the three vegetation types (Fig. 4). Cover type-dependent ranges of the clumping index were derived from in situ measurements of the canopy gap fraction measured with the
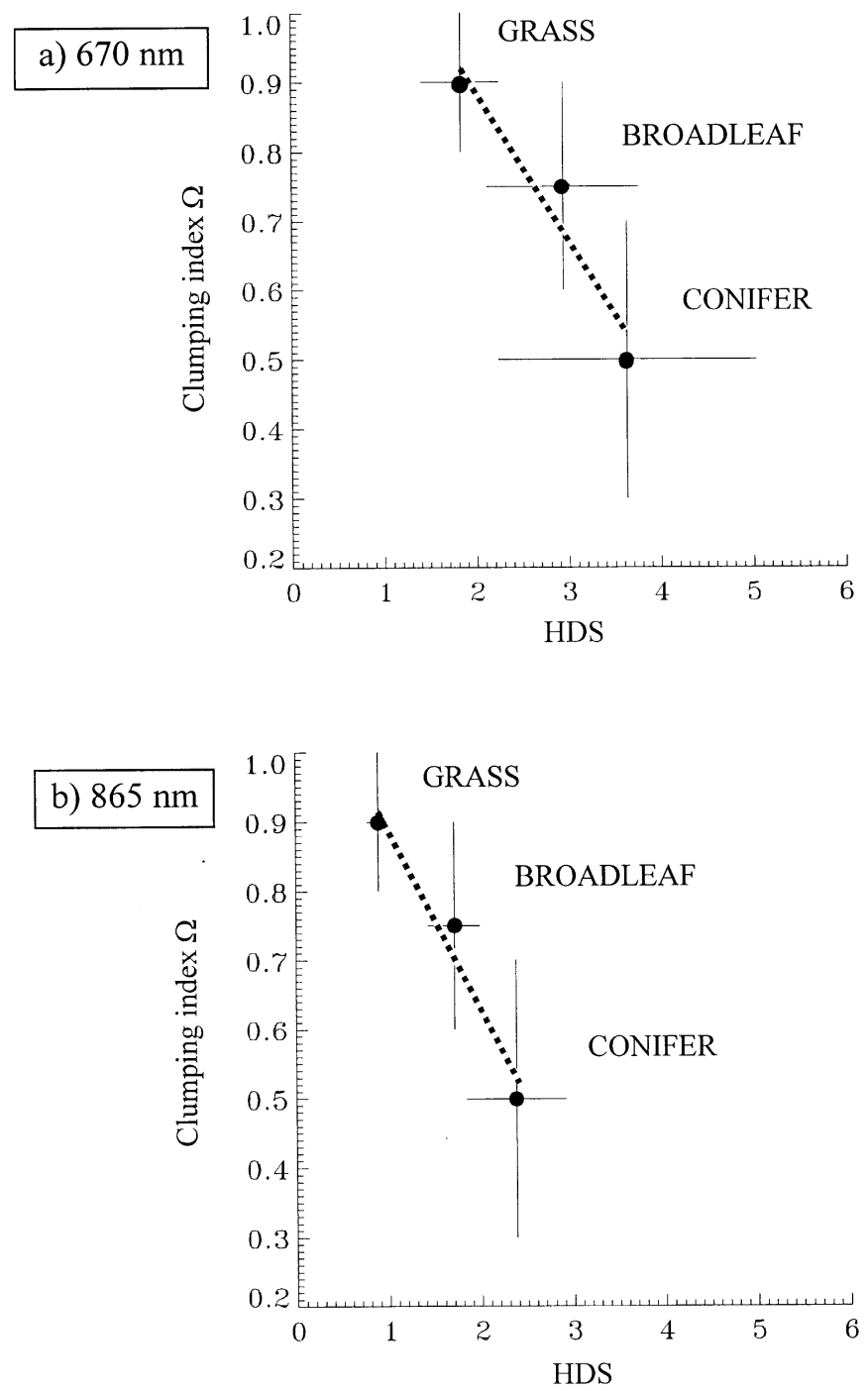

Fig. 4. Variations of the clumping index $\Omega$ as a function of the HDS ratio simulated at $\theta_{\mathrm{S}}=30^{\circ}$ by GHOST model based on spaceborne POLDER observations for three vegetation types at 670 (a) and 865 (b) $\mathrm{nm}$. Error bars indicate the range between the minimum and the maximum values. The results of the linear regressions are represented by $(\boldsymbol{\square})$ 
Table 1

Relationships yielded by linear regressions between the clumping index $\Omega$, the foliage density $\mu$, and the HDS ratio simulated at $\theta_{\mathrm{S}}=30^{\circ}$ by GHOST model based on spaceborne and airborne POLDER data

\begin{tabular}{lcll}
\hline $670 \mathrm{~nm}$ & $r^{2}$ & $865 \mathrm{~nm}$ & $r^{2}$ \\
\hline Spaceborne & & & \\
$\Omega=1.316-0.214 * \mathrm{HDS}$ & .925 & $\Omega=1.157-0.265 * \mathrm{HDS}$ & .960 \\
Airborne & & & \\
$\Omega=1.130-0.156 * \mathrm{HDS}$ & .823 & $\Omega=1.046-0.400 *$ HDS & .681 \\
$\mu=-0.665+0.413 * \mathrm{HDS}$ & .876 & $\mu=-0.085+0.845 *$ HDS & .602 \\
\hline
\end{tabular}

TRAC instrument (Chen \& Cihlar, 1995a; 1995b). The clumping index for grassland was between 0.8 and 1 , which is close to the random case. Conifer forests were generally highly clumped and $\Omega$ is low (between 0.3 and 0.7 ). The broadleaf forest was an intermediate case, with the clumping index being within the range 0.6-0.9. The HDS ratio was scaled between the minimum and the maximum values given by the GHOST simulations. The visible waveband region - in which the effects of multiply scattered light are less important, shadows are darker, and directional effects are larger - displays a large variation in values of HDS (Fig. 4a). The lower magnitude and dynamic range of the HDS in the near infrared band can be attributed to the multiple scattering effects, which act as reducing contrasts between the signature of cover (Fig. 4b).

The largest HDS standard deviation occurs for conifer forests because this cover type is most variable in density and species. This is not the case for grassland pixels, which are very similar, whereas the deciduous forest patches represent intermediate cases. At $670 \mathrm{~nm}$, the range of conifer HDS strongly overlaps with the values of broadleaf HDS, whereas the latter also overlap with the grassland range (Fig. 4a). At $865 \mathrm{~nm}$, the variation range of HDS for grassland and forests are clearly separated and the overlap between HDS values of broadleaf and conifer is weak but the signal dynamic is more reduced (Fig. 4b). Hence, the visible band seems better suited to discriminate vegetation cover types. Fig. $4 \mathrm{a}$ and $\mathrm{b}$ show that as the clumping index decreases, which means more aggregated foliage, the HDS ratio increases. This result validates the hypothesis that the directional index HDS can be useful to discriminate the vegetation types and to retrieve their foliage clumping index. A linear regression is applied and the relationships are formulated in Table 1.

We achieved the same study using airborne POLDER data. Comparisons between GHOST simulations and POLDER measurements have been presented in Lacaze and Roujean (2001). Concerning the origin of the dark spot, similar conclusions were reached that geometric effects could only explain the signature as for spaceborne POLDER observations. Likewise, the clumping index decreases as the HDS increases and it confirms the potential of visible measurements for deriving the clumping index (Fig. 5). The airborne data allow also to clearly discriminate the conifer sites with the largest HDS values. However, we can note an opposite trend between YJP, OJP, and OBS sites. Indeed, the jack pines display a higher aggregation of needles to shoot, especially the young trees (Chen, Rich, Gower, Norman, \& Plummer, 1997). Consequently, for the same amount of foliage in the crown, the probability of light penetration increases and the HDS ratio decreases. Linear relationships are established between the HDS ratio and $\Omega$ as the best fit (Table 1).

The foliage density is controlled by the crown volume, which varies significantly with the tree type. Then, the foliage density $\mu\left(\mathrm{m}^{-1}\right)$ is a relevant variable with which to discriminate species. The $\mu$ values of OA, OBS, OJP, and YJP are derived from in situ measurements of LAI (Chen et al., 1997) and ground estimates of stem density and architectural parameters of trees (Chen \& Leblanc, 1997, Eq. (24)). Fig. 6 shows that the foliage density increases with
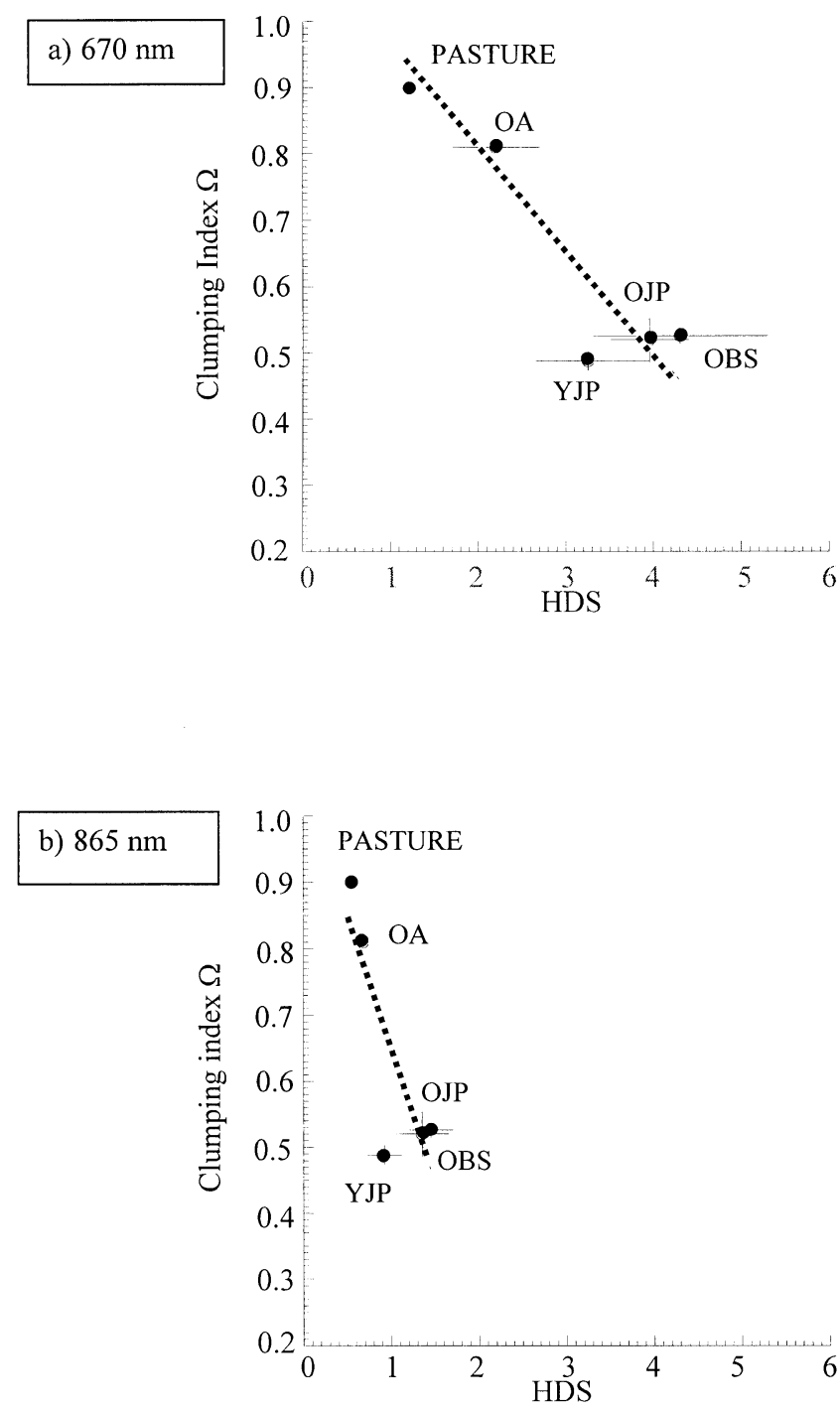

Fig. 5. Variations of the clumping index $\Omega$ as a function of the HDS ratio simulated at $\theta_{\mathrm{S}}=30^{\circ}$ by GHOST model based on airborne POLDER observations at 670 (a) and 865 (b) $\mathrm{nm}$. Error bars indicate the range between the minimum and the maximum values. The results of the linear regressions are represented by $(\boldsymbol{\square})$ 

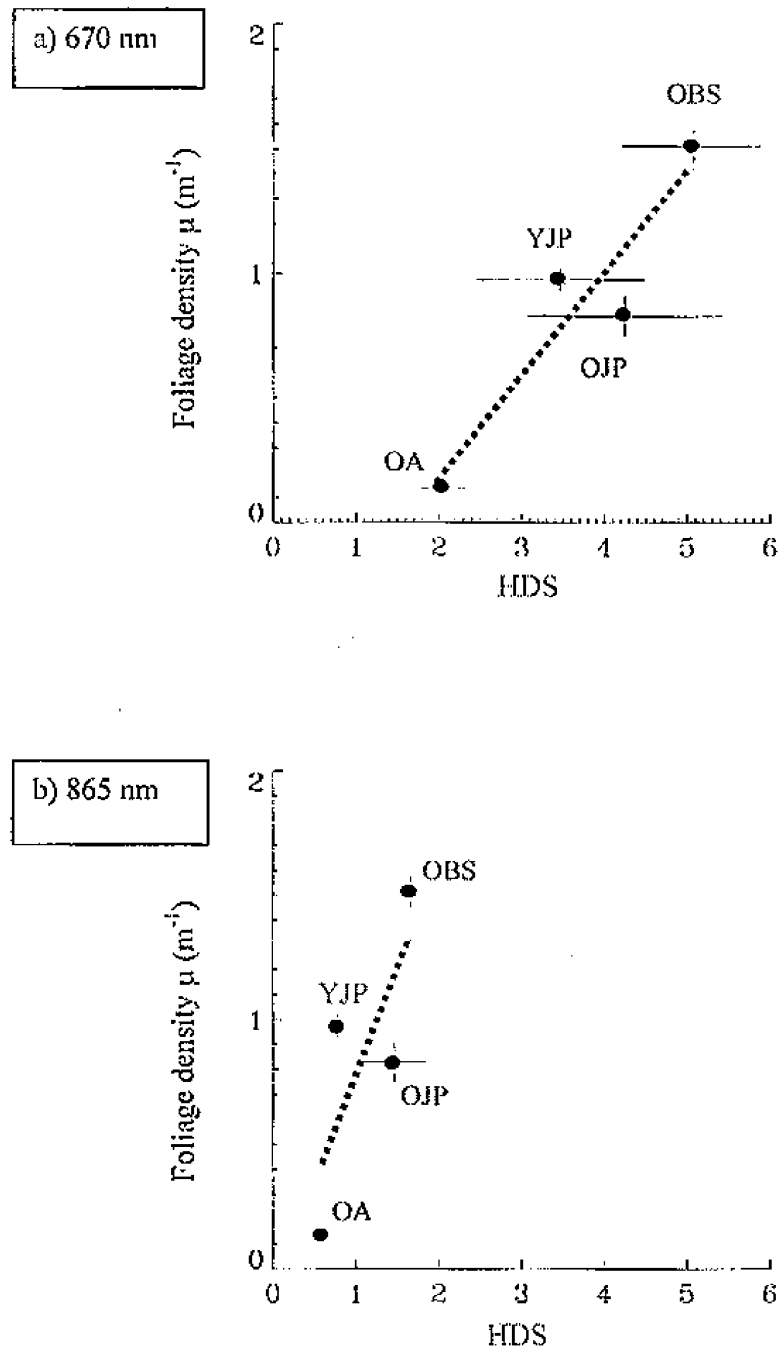

Fig. 6. Variations of the foliage density $\mu$ as a function of the HDS ratio simulated at $\theta_{\mathrm{S}}=30^{\circ}$ by GHOST model based on airborne POLDER observations at 670 (a) and 865 (b) $\mathrm{nm}$. Error bars indicate the range between the minimum and the maximum values. The results of the linear regressions are represented by

the HDS ratio. A dense crown reduces the penetration of incident radiation in the viewing direction; the sensor only sees shaded elements. This effect creates a low dark spot reflectance and a large HDS. Results of the linear regression between $\mu$ and HDS are presented in Table 1 .

There exist differences between spectral HDS values derived from both POLDER data sets (Figs. 4 and 5). First, it could be attributed to atmospheric effects, which had a low impact on airborne POLDER data. It could explain the more sensitivity of near infrared band to the variation of the ground resolution since local BRDF features are better observed in the red wavelength when the blurring effect due to multiple scattering is minimized. This could support the fact that the slopes of the relationships between $\Omega$ and HDS at 670 and $865 \mathrm{~nm}$ are very similar for spaceborne observations as compared to airborne measurements (Table 1). Furthermore, the mean HDS values from spaceborne data are generally larger than the ones retrieved from airborne observations, except for conifers sites at $670 \mathrm{~nm}$. The differences between airborne and spaceborne HDS values are enhanced at $865 \mathrm{~nm}$. It demonstrates that the near infrared waveband is more sensitive to the variation of the ground resolution.

\section{Application to ecological studies}

The importance of the clumping index in ecological applications is inferred from Eq. (2) for calculating the radiation penetration through a plant canopy (Nilson, 1971). That is,

$P(\theta)=\mathrm{e}^{-G(\theta) \mathrm{LAI} \Omega / \cos \theta}$

where $P(\theta)$ is the probability of light penetration through the canopy at zenith angle $\theta$ and $G(\theta)$ is the projection coefficient determined by the leaf angle distribution. The clumping index $\Omega$ characterizes the spatial distribution pattern of leaves. The importance of $\Omega$ is twofold as illustrated in the following cases:

Case 1: In the case of direct measurements, reasonably accurate LAI values can be obtained using allometric equations established from destructive sampling (Gower et al., 1997). From such methods with a disregard to the clumping effect, LAI is derived correctly but large errors are induced in estimating the radiation absorbed by the canopy. In the typical case of a boreal conifer forest, for example, $\mathrm{LAI}=3$ and $\Omega=0.5$. Assuming a random distribution and thus $G(\theta)=0.5$, the probability of radiation penetration through the canopy at $\theta=45^{\circ}$ will be 0.12 for no clumping $(\Omega=1.0)$ against 0.35 for clumping $(\Omega=0.5)$. In such a case, the error estimate of radiation absorption by the canopy will be above $20 \%$. For net primary productivity (NPP), which is approximately proportional to the absorbed radiation under nonstressed conditions (see Monteith, 1972), the error will be of the same order.

Case 2: In the case of indirect measurements, LAI is measured using optical instruments without considering the clumping effect. Optical instruments, such as the LAI-2000, measure canopy gap fractions from the penetration of light at various angles. These gap fraction values are then inverted to obtain LAI assuming a random spatial distribution of leaves $(\Omega=1$; see Chen et al., 1997). In this case, what is measured is in fact the effective LAI, $\mathrm{LAI}_{\mathrm{e}}=\mathrm{LAI} \Omega$. Note that LAI-2000 measures a plant area index and that some developments are usually necessary to get the LAI. The total absorbed radiation by the canopy will be accurate, but the ratio of shaded to sunlit leaves will vary greatly with the clumping index, independently of $\mathrm{LAI}_{e}$. If the proportion of absorbed radiation is shared among shaded leaves in the canopy, the NPP is often higher as the light use efficiency is higher at lower radiation levels. In other words, since the photosynthesis response to light is not linear and 
saturates at high levels of radiation, the sum of photosynthesis is generally higher when more leaves share the same radiation. Such hypothesis is tested using BEPS (Liu, Chen, Cihlar, \& Chen, 1999) against a data set from the OBS site with the daily meteorological data for the whole year of 1994 considered in this test. BEPS uses sunlit/shaded leaf separation methodology in the calculations of NPP. With $\mathrm{LAI}=4, \Omega=0.5$ (Chen, Liu, Cihlar, \& Goulden, 1999), and $\mathrm{LAI}_{\mathrm{e}}=2$, the change in NPP with the $\Omega$ value is tested. We found a decrease in NPP by $19 \%$ when $\Omega$ increases from 0.5 to 1.0. In fact, the decrease in NPP results from the increase of $\Omega$, i.e., the number of shaded leaves increases, whereas the number of sunlit leaves remains the same.

Case 2 is particularly relevant in optical remote sensing. It stresses the problem of leaf area underestimation due to shaded leaves or sunlit leaves that are not seen. We therefore tend to measure only the effective LAI from the satellite images with a limited set of viewing angles. In this regard, multiple angle measurements can be used to derive the clumping index. It will enable us to assess not only the total absorbed radiation but also the distribution of the scattered radiation field among leaves within the vegetation canopy. This opportunity greatly improves our ability to model vegetation photosynthesis, which is an important component of the carbon cycle.

\section{Conclusion}

In this paper, the authors presented a methodology to retrieve the clumping index of vegetation canopies from the bidirectional signature. We have used the GHOST model, which has been designed to simulate with good accuracy the hot spot phenomenon over different vegetation types. GHOST simulations served to compute the directional index HDS defined as the normalized difference between the maximum and minimum of reflectance in the principal plane. This ratio appears to be an inherent property of the vegetation cover types, and it has been shown to be related to clumping. The method was found relevant for both spaceborne and airborne POLDER observations. In the latter case, a relationship between the hot spot shape and foliage density was established for selected BOREAS sites.

The work using POLDER/ADEOS measurements has been achieved for three major vegetation types of Canada having unique clumping index values. The next step will be to investigate other canopies located in other areas climatic environments such as shrub land, woodland, evergreen broadleaf forest, and tropical forest, which are representative of major ecosystems. Likewise, the relationships have been established for "pure" pixels but the same method could be applied to signatures of mixed pixels in order to analyze the behavior of the hot spot shape according to the portion of each vegetation type.

The GHOST model is able to simulate the bidirectional signatures collected at high and coarse ground resolution.
Thereby, GHOST seems an appropriate tool to analyze data of spaceborne multidirectional sensors such as MISR/ TERRA and POLDER/ADEOS2 and take benefit of the geographic statistical distribution of the hot spot, which should lead to a global mapping of clumping factors. In refining the LAI assessment, it will serve to improve the estimation of the NPP of ecosystems and the characterization of surface conditions in meteorological models.

\section{Acknowledgments}

The lead author wishes to thank Josef Cihlar and the people at the Canada Center of Remote Sensing for their assistance during a 3-month stay, at which time a portion of this work was done. The authors feel indebted to the two anonymous reviewers for their useful comments and suggestions. RL has received doctoral financial support from the Ministère de l'Enseignement Supérieur et de la Recherche and is currently under a postdoctoral position of the Centre National d'Etudes Spatiales. JLR is with the Centre National de la Recherche Scientifique.

\section{Appendix A}

The canopy is structured as a semiinfinite slab of conicshaped turbid crowns above very thin trunks. A single crown encompasses both randomly distributed shoots and woody material contributing to the mean single scattering albedo $\omega$ and effective $\mathrm{LAI}_{\mathrm{e}}$. The GHOST model simulates the reflectance term as the sum of single scattering $\left(\rho_{\mathrm{ss}}\right)$ and multiple scattering $\left(\rho_{\mathrm{ms}}\right)$ components for vegetation and of the soil contribution $\left(\rho_{\text {soii }}\right)$ as follows:

$$
\begin{aligned}
\rho_{\text {direct }}= & \rho_{\mathrm{ss}}+\rho_{\mathrm{ms}}+\rho_{\text {soil }} \\
\rho_{\mathrm{ss}}= & \frac{\omega}{4} \frac{1}{\mu_{\mathrm{S}} \mu_{\mathrm{V}}} * P(\xi) * \frac{1}{\Delta} \\
& *\left(1-\mathrm{e}^{-\Delta \mathrm{LAI}_{\mathrm{e}}}\right) \quad \text { with } P(\xi) \\
= & \frac{8}{3 \pi}\left[\left(\frac{\pi}{2}-\xi\right) \cos \xi+\sin \xi\right] \\
\rho_{\mathrm{ms}}= & \frac{\omega}{4} \frac{1}{\mu_{\mathrm{S}} \mu_{\mathrm{V}}} *\left[H\left(\mu_{\mathrm{S}}\right) H\left(\mu_{\mathrm{V}}\right)-1\right] * \frac{1}{\Delta^{\prime}} \\
& *\left(1-\mathrm{e}^{-\Delta \mathrm{LAI}_{\mathrm{e}}}\right) \text { with } H\left(\mu_{\mathrm{S}, \mathrm{V}}\right) \\
= & \frac{1+2 \mu_{\mathrm{S}, \mathrm{V}}}{1+2 \mu_{\mathrm{S}, \mathrm{V}} \sqrt{1-\omega}} \\
\rho_{\text {soil }}= & \rho_{\theta} * \mathrm{e}^{-\Delta^{\prime} \mathrm{LAI}}
\end{aligned}
$$

where $\rho_{\theta}$ is the background reflectivity (Eqs. (A1-4)). The phase function $P(\xi)$ (see Ross, 1981) assumes here the same 
reflectance and transmittance for the canopy elements. The function $H\left(\mu_{\mathrm{S}, \mathrm{V}}\right)$ is from Hapke (1981) and the term $\Delta$ models the hot spot effect (see Roujean, 2000). It reduces to the well-known expression $\Delta^{\prime}$ for the case of multiple scattering as the hot spot effect poorly affects the higher orders of scattering (Hapke, 1986; Qin \& Goel, 1995). That is (Eqs. (A5) and (A6)):

$$
\Delta=\sqrt{\frac{G_{\mathrm{S}}^{2}}{\mu_{\mathrm{S}}^{2}}+\frac{G_{\mathrm{V}}^{2}}{\mu_{\mathrm{V}}^{2}}-2 \frac{G_{\mathrm{S}} G_{\mathrm{V}}}{\mu_{\mathrm{S}} \mu_{\mathrm{V}}} \cos \xi}
$$

$\Delta^{\prime}=\frac{G_{\mathrm{S}}}{\mu_{\mathrm{S}}}+\frac{G_{\mathrm{V}}}{\mu_{\mathrm{V}}}$

The architectural properties enter into the parameterization of the G-function controlling the shape of the hot spot. The formulation of the G-function is derived from the TwoStory Equations of Transmission of Solar Energy (TSETSE; Roujean, 1999) model and it is expressed as the contribution of a volume component $G_{\mathrm{vol}}$, representing the random arrangement of elements (shoots and branches) within a crown, and a geometric component $G_{\text {geo }}$ accounting for the shape and dimension of the crown. This latter component relies on a form factor $f_{\text {geo }}$, which is developed as a function of the tree height $H$, the crown basis height $H_{\mathrm{C}}$, the crown diameter $d_{\mathrm{C}}$, the mean trunk distance $d_{\mathrm{T}}$, and an angle $\theta_{\mathrm{C}}$, which stands locally for the half apex angle of the crown or the mean gap fraction at patch scale. The G-function results from the empirical addition of the two components (Eqs. $(\mathrm{A} 7-10))$ :

$G_{\mathrm{S}, \mathrm{V}}=G_{\mathrm{vol}}+G_{\mathrm{geo}}=0.5+0.5 * \mathrm{e}^{-f_{\mathrm{geo}}}$

with

$f_{\text {geo }}=\frac{H-H_{\mathrm{C}}}{d_{\mathrm{T}}} * \frac{\tan ^{2}\left(\theta_{S}-\theta_{\mathrm{c}}\right)}{1-\gamma\left(1-2 z_{\min }\right)}$

where

$z_{\min }=\mathrm{e}^{-\left(\frac{d_{\mathrm{T}}}{\left(H-H_{\mathrm{C}}\right)\left(\tan \theta_{\mathrm{S}}-\tan \theta_{\mathrm{C}}\right)}\right)^{2}}$

and

$\gamma=\frac{d_{\mathrm{C}}}{d_{\mathrm{T}}}$

The GHOST model is applicable to other vegetations like grassland and crops. In such case, the variable $H_{\mathrm{C}}$ is fixed to zero and the diameter $d_{\mathrm{C}}$ is adjusted to represent the mean stem dimension.

\section{References}

Asner, G. P. (2000). Contributions of multi-view angle remote sensing to land surface and biogeochemical research. Remote Sensing Reviews, 18, $137-162$.

Asner, G. P., Braswell, B. H., Schimel, D. S., \& Wessman, C. A. (1991). Ecological research needs from multi-angle remote sensing data. Remote Sensing of Environment, 63, 155-165.

Bréon, F. M., \& Colzy, S. (1999). Cloud detection from the space-borne POLDER instrument and validation against surface synoptic observations. Journal of Applied Meteorology, 38 (6), 777-785.

Bréon, F. M., Vanderbilt, V., Leroy, M., Bicheron, P., Walthall, C. L., \& Kalshoven, J. E. (1997). Evidence of hot spot directional signature from airborne POLDER measurements. IEEE Transactions on Geosciences and Remote Sensing, 35, 479-484.

Chen, J. M. (1996). Optically-based methods for measuring seasonal variation of leaf area index in boreal conifer stands. Agriculture and Forest Meteorology, 80, 135-163.

Chen, J. M., \& Black, T. A. (1991). Measuring leaf area index of plant canopies with branch architecture. Agriculture and Forest Meteorology, $57,1-12$.

Chen, J. M., \& Cihlar, J. (1995a). Plant canopy gap size analysis theory for improving optical measurements of leaf area index. Applied Optics, 34, $6211-6222$.

Chen, J. M., \& Cihlar, J. (1995b). Quantifying the effect of canopy architecture on optical measurements of leaf area index using two gap size analysis methods. IEEE Transactions on Geosciences and Remote Sensing, 33, 777-787.

Chen, J. M., Chen, W., Liu, J., \& Cihlar, J. (2000). Annual carbon balance of Canada forests during 1895-1996. Global Biogeochemical Cycles, 14 (3), 839-850.

Chen, J. M., Liu, J., Leblanc, S. G., Roujean, J. L., \& Lacaze, R. (2001). Utility of multi-angle remote sensing for terrestrial carbon cycle modeling. Proceedings of the 8th International Symposium on Physical Signatures and measurements in Remote Sensing, Aussois, France, 8-13 January, 2001 (pp. 249-258). Publications CNES.

Chen, J. M., \& Leblanc, S. G. (1997). A four-scale bidirectional reflectance model based on canopy architecture. IEEE Transactions on Geosciences and Remote Sensing, 35 (5), 1316-1337.

Chen, J. M., Liu, J., Cihlar, J., \& Goulden, M. L. (1999). Daily canopy photosynthesis model through temporal and spatial scaling for remote sensing applications. Ecological Modeling, 124, 99-119.

Chen, J. M., Rich, P. M., Gower, S. T., Norman, J. M., \& Plummer, S. (1997). Leaf area index of boreal forest: theory, techniques, and measurements. Journal of Geophysical Research, 102, 9429-29443.

Cihlar, J., Beaubien, J., Latifovic, R., \& Simard, G. (1999). Land cover of Canada 1995 version 1.1. Digital data set documentation, Natural Resources Canada, Ottawa, Ontario. ftp://ftp2.ccrs.nrcan.gc.ca/ftp/ad/ EMS/landcover95/.

Cihlar, J., Denning, A. S., \& Gosz, J. (2000). Terrestrial carbon observation synthesis. Report of an International Workshop, Ottawa, Canada, $8-11$ February, available at ftp://ftp2.ccrs.nrcan.gc.ca/ftp/ad/EMS/ TCO.

Deschamps, P. Y., Bréon, F. M., Leroy, M., Podaire, A., Bricaud, A., Buriez, J. C., \& Sèze, G. (1994). The POLDER mission: instrument characteristics and scientific objectives. IEEE Transactions on Geosciences and Remote Sensing, 32, 598-615.

Diner, D. J., Asner, G. P., Davies, R., Knyazikhin, Y., Muller, J. P., Nolin, A. W., Pinty, B., Schaaf, C. B., \& Stroeve, J. (1999). New directions in Earth observing: scientific application of multi-angle remote sensing. Bulletin of the American Meteorological Society, 80, 2209-2228.

Field, C. B., Randerson, J. T., \& Malmstrom, C. M. (1995). Global net primary production: combining ecology and remote sensing. Remote Sensing of Environment, 51, 74-88.

Gerstl, S. A. W., Simmer, C., \& Powers, B. J. (1986). The canopy hotspot as crop identifier. In: Symposium on remote sensing of resources devel- 
opment and environment management (2 (1), pp. 261-263) (Enschede, F.R.G., August).

Gower, S. T., Vogel, J. G., Norman, J. M., Kucharik, C. J., Steele, S. J., \& Stow, T. K. (1997). Carbon distribution and aboveground net primary production in aspen, jack pine, and black spruce stands in Saskatchewan and Manitoba, Canada. Journal of Geophysical Research, 102, 29029-29041.

Hapke, B. (1981). Bidirectional reflectance spectroscopy: 1. Theory. Journal of Geophysical Research, 86, 3039-3054.

Hapke, B. (1986). Bidirectional reflectance spectroscopy: 4. The extension coefficient and the opposition effect. Icarus, 67, 264-280.

Hautecoeur, O., \& Leroy, M. (1998). Surface bidirectional reflectance distribution function observed at global scale by POLDER/ADEOS. Geoscience Research Letters, 25, 4197-4200.

Herman, M., Deuzé, J. L., Devaux, C., Bréon, F. M., \& Tanré, D. (1997). Remote sensing of aerosol over land surface, including polarization measurements; application to some airborne POLDER measurements. Journal of Geophysical Research, 102, 17039-17050.

Jupp, D. L. B., \& Strahler, A. H. (1991). A hotspot model for leaf canopies. Remote Sensing of Environment, 38, 193-210.

Kuusk, A. (1985). The hot spot effect of a uniform vegetative cover. Soviet Journal of Remote Sensing, 3, 645-658.

Lacaze, R., \& Roujean, J. L. (2001). G-function and HOt SpoT (GHOST) reflectance model: application to multi-scale airborne POLDER data. Remote Sensing of Environment, 76, 67-80.

Leroy, M., Deuzé, J. L., Bréon, F. M., Hautecoeur, O., Herman, M., Buriez, J. C., Tanré, D., Bouffiès, S., Chazette, P., \& Roujean, J. L. (1997). Retrieval of atmospheric properties and surface bidirectional reflectances over land from POLDER/ADEOS. Journal of Geophysical Research, 102, 17023-17037.

Leroy, M., \& Roujean, J. L. (1994). Sun and view angle corrections on reflectances derived from NOAA/AVHRR data. IEEE Transactions on Geosciences and Remote Sensing, 32 (3), 684-697.

Liu, J., Chen, J. M., Cihlar, J., \& Chen, W. (1999). Net primary productivity distribution in the BOREAS region from a process model using satellite and surface data. Journal of Geophysical Research, 104, 27735-27754.

Liu, J., Chen, J. M., Cihlar, J., \& Park, W. M. (1997). A process-based boreal ecosystem productivity simulator using remote sensing inputs. Remote Sensing of Environment, 62, 158-175.

Monteith, J. L. (1972). Solar radiation and productivity in tropical ecosystem. Journal of Applied Ecology, 9, 746-766.
Ni, W., Li, X., Woodcock, C. E., Roujean, J. L., \& Davis, R. E. (1997). Transmission of solar radiation in boreal conifer forests: measurements and models. Journal of Geophysical Research, 102, 29555-29566.

Nilson, T. (1971). A theoretical analysis of the frequency of gaps in plant stands. Agriculture and Forest Meteorology, 8, 25-38.

Oker-Blom, P., Lappi, J., \& Smolander, H. (1991). Radiation regime and photosynthesis of coniferous stands. In: R. B. Myneni, \& J. Ross (Eds.), Photon-vegetation interactions - application in optical remote sensing and plant ecology. New York: Springer-Verlag.

Qin, W., \& Goel, N. S. (1995). An evaluation of hot spot models for vegetation canopies. Remote Sensing Reviews, 13, 121-195.

Qin, W., \& Xiang, Y. (1994). On the hot spot effect of leaf canopies: modeling study and influence of leaf shape. Remote Sensing of Environment, 50, 95-106.

Ross, J. K. (1981). The radiation regime and architecture of plants stands. Norwell, MA: Dr W. Junk (391 pp.).

Roujean, J. L. (1999). Two-Story Equations of the Transmission of Solar Energy (TSETSE) in open boreal conifer tree stands. Journal of Geophysical Research, 104, 27869-27879.

Roujean, J. L. (2000). A parametric hot spot model for optical remote sensing applications. Remote Sensing of Environment, 71 (2), 197-206.

Running, S. W., Loveland, T. R., \& Pierce, L. L. (1994). A vegetation classification logic based on remote sensing for use in global biogeochemical models. Ambio, 23, 77-89.

Sandmeier, S., \& Deering, D. W. (1999). Structure analysis and classification of boreal forests using hyper-spectral BRDF data from ASAS. Remote Sensing of Environment, 69 (3), 281-295.

Schimel, D. S. (1995). Terrestrial ecosystems and the carbon cycle. Global Change Biology, 1, 77-91.

Sellers, P. J., et al. (1997). BOREAS in 1997: experiment overview, scientific results and future directions. Journal of Geophysical Research, 102, 28731-28769.

Vermote, E. F., Tanré, D., Deuzé, J. L., Herman, M., \& Morcrette, J. J. (1997). Second simulation of the satellite signal in the solar spectrum, 6S: an overview. IEEE Transactions on Geosciences and Remote Sensing, 35, 675-686.

Verstraete, M. M., Pinty, B., \& Dickinson, R. E. (1990). A physical model of the bidirectional reflectance of vegetation canopies: 1 . Theory. Journal of Geophysical Research, 95, 11755-11765. 